\title{
Article
}

\section{Pharmacist prescribing: a cross-sectional survey of the views of pharmacists in Nigeria}

\author{
Auta, Asa, Strickland-Hodge, Barry, Maz, Julia and David, Shalkur \\ Available at http://clok.uclan.ac.uk/17903/ \\ Auta, Asa ORCID: 0000-0001-6515-5802, Strickland-Hodge, Barry, Maz, Julia \\ and David, Shalkur (2018) Pharmacist prescribing: a cross-sectional survey of \\ the views of pharmacists in Nigeria. International Journal of Pharmacy \\ Practice, 26 (2). pp. 111-119. ISSN 0961-7671
}

It is advisable to refer to the publisher's version if you intend to cite from the work. http://dx.doi.org/10.1111/jpp.12381

For more information about UCLan's research in this area go to http://www.uclan.ac.uk/researchgroups/ and search for <name of research Group>.

For information about Research generally at UCLan please go to http://www.uclan.ac.uk/research/

All outputs in CLoK are protected by Intellectual Property Rights law, including Copyright law. Copyright, IPR and Moral Rights for the works on this site are retained by the individual authors and/or other copyright owners. Terms and conditions for use of this material are defined in the policies page.

\section{CLoK}

Central Lancashire online Knowledge www.clok.uclan.ac.uk

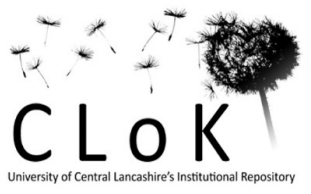


Pharmacist prescribing: a cross-sectional survey of the views of pharmacists in Nigeria

Asa Auta ${ }^{1}$

${ }^{1}$ School of Pharmacy and Biomedical Sciences, University of Central Lancashire, Preston, PR1 2HE, UK

Barry Strickland-Hodge ${ }^{2}$

${ }^{2}$ School of Healthcare, Faculty of Medicine and Health, University of Leeds, Leeds, LS2 9JT, UK.

Julia Maz ${ }^{2}$

${ }^{2}$ School of Healthcare, Faculty of Medicine and Health, University of Leeds, Leeds, LS2 9JT, UK.

Shalkur David ${ }^{3}$

${ }^{3}$ Department of Clinical Pharmacy, Faculty of Pharmaceutical Sciences, University of Jos, Jos, Nigeria.

Corresponding author: Asa Auta, School of Pharmacy and Biomedical Sciences, University of Central Lancashire, Preston, PR1 2HE, UK. Email: aauta@uclan.ac.uk 


\section{Abstract}

Objectives: This study was carried out to: 1 ) explore the views of pharmacists in Nigeria on the extension of prescribing authority to them and determine their willingness to be prescribers 2) identify the potential facilitators and barriers to introducing pharmacist prescribing in Nigeria.

Method: An online cross-sectional survey was conducted from August to October 2014 among 775 pharmacists recruited from the Facebook group of the Pharmaceutical Society of Nigeria using a simple random technique. The questionnaire used for the survey was developed based on the review of the literature and previous qualitative studies conducted in Nigeria. The instrument was evaluated for content validity by two external pharmacy practice researchers and the reliability of items assessed using internal consistency tests. Data obtained from the survey were entered into SPSS v.22 and descriptive statistics were generated. Relationships between variables were evaluated using the chi-square test and $p<0.05$ was considered statistically significant.

Key findings: The response rate was 40.6\% (315/775). Three hundred and six (97.1\%) respondents agreed that pharmacists should be given prescribing authority. Of these 306, 295 (96.4\%) were willing to be prescribers and just over half of them (148/295; $50.2 \%$ ) would prefer to prescribe in collaboration with medical doctors. Of those willing to be prescribers, $285(96.6 \%)$ reported that they would need additional training. The most perceived areas of training needed were in the principles of differential diagnosis (81.4\%), pathophysiology of diseases (74.0\%) and interpretation of laboratory results (68.1\%). Respondents identified increasing patients' access to care (308/315; 97.8\%) and better utilisation of pharmacists' skills (307/315; 97.5\%) as the most likely facilitators to pharmacist prescribing in Nigeria. On the other hand, resistance from the medical doctors (299/315; 94.9\%) and pharmacists' inadequate skills in diagnosis (255/315; 81.0\%) were perceived as the most likely barriers.

Conclusion: Pharmacist prescribing represents an opportunity to promote patients' access to care and the utilisation of pharmacists' skills in Nigeria. The majority of pharmacists showed a positive attitude towards pharmacist prescribing and were willing to be prescribers. The findings of this study could potentially contribute to future medicine prescribing policy and pharmacy practice in Nigeria.

Keywords: pharmacist prescribing, pharmacists' attitude, role development, Nigeria 


\section{Introduction}

Prescribing to patients has traditionally been under the professional domain of doctors and dentists, until the introduction of non-medical prescribing (NMP) in some countries which allowed non-medical professionals including nurses, pharmacists, optometrists and physiotherapists to prescribe medicines. ${ }^{[1,2]}$ Nurse prescribing is the most prevalent form of NMP worldwide. Available data shows that Nurses have been authorised to prescribe in 22 countries including the United States of America (USA), United Kingdom (UK), Australia, New Zealand, Canada, Sweden, the Republic of Ireland, South Africa, Botswana, Kenya and Uganda.[1] Pharmacists are legally allowed to prescribe medicines in the United States, United Kingdom, Canada, New Zealand and Israel. ${ }^{[2,3]}$ However, a 2009 global survey of hospital pharmacy practice revealed that hospital pharmacists in 20 countries are involved in the prescribing of medicines under certain local arrangements in emergency situations. ${ }^{[4]}$ For instance, in Anguilla and Argentina, designated pharmacists are allowed to prescribe narcotic analgesics to cancer patients in an emergency. ${ }^{[5]}$

There are different models of pharmacist prescribing including independent, supplementary and collaborative prescribing models. ${ }^{[2]}$ In the independent prescribing model, the pharmacist is independently and legally responsible for the assessment of patients with diagnosed or undiagnosed conditions and for his or her prescribing decisions. Supplementary and collaborative prescribing models have similar features as the prescribing pharmacist prescribes in partnership with an independent prescriber usually a doctor or dentist, who makes the diagnosis and initial treatment decisions. ${ }^{[2]}$ However, in the supplementary prescribing model, prescribing by pharmacists including modification and continuation of therapy is achieved using a patient-specific clinical management plan (CMP). The CMP is agreed by the independent and supplementary prescribers as well as the patient. The scope of prescribing authority accorded to pharmacists differs from one country to another. For example, in the UK, pharmacists can prescribe any medicine within their area of competence except cocaine, dipipanone and diamorphine for treating addiction, ${ }^{[6]}$ while in Alberta, Canada, pharmacists with additional prescribing authorization can prescribe any medicines within their area of competence except those covered under the Controlled Drugs and Substances Act including narcotics. ${ }^{[7,8]}$

Despite the challenges associated with the implementation of pharmacist prescribing including opposition from doctors and limited evidence to demonstrate its effectiveness, ${ }^{[9]}$ it is gradually being accepted and implemented internationally. For example, in Canada, 
pharmacist prescribing started in 2007 in the Alberta province and by 2012 all the provinces except Quebec had granted prescribing authority to pharmacists. ${ }^{[8]}$ Furthermore, pharmacists in many countries, where pharmacist prescribing has not been legalised are keen in taking on an extended role in prescribing. For example, in an Australian survey, $83.9 \%$ of the 2592 pharmacists who participated in the study were in favour of a prescribing authority being extended to them. ${ }^{[10]}$ The increase in the international recognition of pharmacist prescribing has been facilitated by the desire to ensure prompt patient access to prescription medicines and better utilisation of pharmacists' skills. ${ }^{[9]}$ Various stakeholders including doctors, pharmacists, patients, and policymakers have reported an increase in patients' access to treatment as a result of NMP. ${ }^{[11,12]}$ In addition, pharmacists have reported a positive impact on their role to include: enhanced job satisfaction; better use of their clinical skills; integration of pharmacists into the patient management team and more autonomy and responsibility in patient management as a result of pharmacist prescribing. ${ }^{[11,13]}$

In Nigeria, only medical doctors, dentists and some designated nurses and community health workers in community-based primary health centres (PHCs) have the legal right to prescribe medicines. ${ }^{[14]}$ However, prescribing by nurses and community health workers has been reported to be inappropriate for a number of reasons including lack of adherence to treatment guidelines and their inadequate knowledge of medicines. ${ }^{[15,16]}$ For example, prescribing antibiotics for the treatment of viral respiratory infections has been reported to be common. ${ }^{[15,16]}$

In hospitals in Nigeria, the general out-patient departments (GOPDs) serve as the entry points for most patients seeking medical help because of the lack of doctors in PHCs. ${ }^{[3,17]}$ These GOPDs function more or less like the general practitioner (GP) practices in the UK. Typically, a doctor in a GOPD in Nigeria has approximately 40 - 50 patient consultations per day because of the shortage of doctors. ${ }^{[17,18]}$ In addition, more than $50 \%$ of patients visiting GOPDs wait for between one to three hours to see a doctor. ${ }^{[17,18]}$ As a result, access to prescription medicines in Nigeria can be seriously affected by the shortage of medical prescribers (4 doctors per 10,000 people compared with 28 doctors per 10,000 people in the UK) including general practitioners and specialist physicians and long waiting times in hospitals. ${ }^{[15,19]}$

Pharmacists in Nigeria are highly educated professionals with expertise in medicines management. However, their expertise is not used effectively as their roles have not been expanded to a more clinical one. They mainly perform the traditional role of dispensing, which could be handled by suitably trained pharmacy technicians as in other 
countries such as the UK. ${ }^{[20]}$ Pharmacists in Nigeria have shown a willingness for expanded clinical roles including prescribing. ${ }^{[3,21]}$ Our qualitative study involving semistructured interviews with 43 Nigerian stakeholders including policymakers, doctors, pharmacists and patient group representatives revealed strong support for the introduction of pharmacist prescribing in Nigeria by participants who were not doctors especially pharmacists. ${ }^{[3]}$ However, the findings of this study cannot be generalised because of the small sample size. Therefore the aim of this study was to: 1) explore the views of pharmacists in Nigeria on the extension of prescribing authority to them and determine their willingness to be prescribers and 2) identify the potential facilitators and barriers to introducing pharmacist prescribing in Nigeria

\section{Methods}

\section{Study design}

A cross-sectional survey was conducted from September to October 2014 among pharmacists in Nigeria using an online self-completion questionnaire as the data collection instrument.

\section{Ethical approval}

Ethical approval for this study was granted by the School of Healthcare Research Ethics Committee, University of Leeds, UK and the Plateau State Specialist Hospital Health Research Ethics Committee, Nigeria.

\section{Recruitment of participants}

Participants were recruited from the Facebook group of the Pharmaceutical Society of Nigeria (PSN). PSN is the professional body for pharmacists in Nigeria. PSN's Facebook group had 5,214 members at the time of this survey. Participants for both the pilot and main survey were recruited using a simple random technique. To achieve a random sample, a list of the members of the Facebook group was retrieved in alphabetical order and then numbered serially. Microsoft Excel 2010 was used to generate a list of nonrepeated random numbers which were applied to the PSN's Facebook group list to recruit participants for the online survey. A sample of 695 pharmacists determined using the sample size formula for descriptive studies described by Eng, ${ }^{[22]}$ were invited to participate in the survey. 


\section{Questionnaire development}

The questionnaire was informed by the review of the literature and findings of our qualitative studies conducted with Nigerian stakeholders in relation to extending pharmacists' clinical roles to include prescribing. ${ }^{[3,10,23]}$ It was evaluated for content validity through an iterative review process by two external academic pharmacy practice researchers. The first page of the online survey contained an introductory statement relating to the study. In addition, it contained information on consent and implications of participating in the study. Those who agreed to continue with the survey moved unto the next page of the survey which contained the survey questions. The survey was anonymised and consisted of 62 items which were divided into 3 sections.

The first section of the questionnaire had 8 items and sought to obtain anonymous demographic details of respondents including gender, years of experience, area and place of practice. These data are needed to enable the statistical classification of respondents' views and test for relationship between participants' demographics and views. The second section sought participants' views on clinical pharmacy practice in Nigeria and had 9 items. The third section contained 45 items measuring respondents' views on pharmacist prescribing in Nigeria including their preferred model, willingness to be prescribers, perceived areas of training needs and potential facilitators and barrier. Depending on the survey item, respondents were either asked to respond yes/no or complete a five point Likert scale (strongly agree, agree, unsure, disagree and strongly disagree) to indicate their level of agreement with a statement.

\section{Piloting of questionnaire}

The questionnaire was piloted in August 2014 among a separate sample of 80 pharmacists recruited from the PSN's Facebook group as described above for the main sample. These pharmacists were sent a message through Facebook inviting them to participate in the online pilot survey. Participants were asked to provide feedback to the researcher on any aspect of the survey including style, length, access to the online questionnaire and difficulty faced when completing the online survey. A follow-up message was sent after two weeks thanking those who had completed the survey and requesting those who were yet to participate to please do so.

Of the 80 pharmacists that were contacted for the pilot survey, 41 participants returned completed surveys. Reliability testing of the questionnaire was carried out using Chronbach's alpha $(\alpha)$. The internal consistency of the 25 items measuring the facilitators and barriers to granting prescribing authority to pharmacists in Nigeria was determined 
using SPSS and that gave an $\alpha$ value of 0.745 . The Kuder-Richardson reliability coefficients (KR-20) of the 13 items measuring respondents' perceived areas of training need for pharmacist prescribing was 0.892. Based on the responses to the pilot, no further changes to the questionnaire were found to be necessary. Hence, the data collected were included in the overall results of this study. This was considered acceptable as participants were included in the pilot study based on the same inclusion criteria and sampling technique used for the main survey.

\section{The main survey}

The 695 pharmacists identified for the main survey were invited through a generic recruitment mail sent to their Facebook inbox. The mail contained the link to the survey hosted by the Bristol Online Survey (BOS).

Reminders were sent to all research participants, two weeks after they received the initial invitation mailing. An additional three weeks was allowed to collect responses following the reminder. The survey was closed at the end of October 2014.

\section{Data analysis}

The data collected in this study were imported from the BOS system into the IBM SPSS version 22 for data management and analysis. Descriptive statistics generated using SPSS were used to represent the demographic characteristics of respondents and their views including those on prescribing. Relationships between two variables were evaluated using chi-square test. In tests involving variables in which data were obtained on the five-point Likert scale, respondents' views were rescaled into three categories (strongly agree/agree, unsure and disagree/strongly disagree). This rescaling was done because of the small sample size of the study. In addition, re-categorising respondents' views into three (as opposed to five) in chi-square analysis minimises the probability of making type 2 error (failing to reject the null hypothesis even though there is a difference between the groups in the population) which is usually manifested when the sample size is small or when considering a small sub-group within a large survey. Furthermore, Fisher's exact test was used to determine statistical difference between groups in instances where the groups were small, particularly when the numbers of counts per cell in the contingency table were less than 5 in more than $20 \%$ of the cells. In all the Chisquare and Fisher's exact tests conducted, a p-value of less than 0.05 was considered statistically significant. 


\section{Results}

\section{Response rate}

Of the 695 pharmacists contacted for the main survey (which excluded the 80 already included in the pilot), 316 attempted to complete the survey but only 274 surveys were completely filled while the remaining 42 were partially completed. The 42 partially completed surveys were unusable and therefore excluded from the study. Hence, the response rate for the main study was $39.4 \%$ (274/695). Adding the pilot surveys [pilot response rate of $51.3 \%(41 / 80)]$ to those obtained in the main study yielded an overall response rate of $40.6 \%$ (315/775).

\section{Demographics}

Table 1 presents a summary of the demographic characteristics of respondents. The majority of respondents were male $(197 / 315 ; 62.5 \%)$ and a third had between 6-10 years of experience $(105 / 315 ; 33.3 \%)$ as pharmacists. Twenty eight $(8.9 \%)$ respondents held a master's degree in clinical pharmacy. The majority of respondents were hospital pharmacists (190/315; 60.3\%).

\section{Views on pharmacist prescribing and willingness to be prescribers}

The results of this study revealed strong support for an extended role in prescribing for pharmacists in Nigeria. Three hundred and six (97.1\%) respondents agreed that pharmacists should be given the authority to prescribe medicines. Of these, $96.4 \%$ $(295 / 315)$ were willing to be prescribers. There was no significant difference $(p=0.547)$ between willingness of hospital (95.8\%) and community (97.7\%) pharmacists to be prescribers.

Of those willing to be prescribers, half (148/295) would prefer to prescribe in collaboration with medical doctors (who would diagnose) whilst $10.5 \%$ (31/295) preferred independent prescribing. Just over one-third of these respondents $(111 / 295 ; 37.6 \%)$ would prefer a combination of collaborative and independent prescribing. Prescribing from a limited drug formulary was the least preferred model of prescribing among respondents $(5 / 295$, $1.7 \%)$. The results showed no significant difference $(p=0.491)$ between hospital and community pharmacists in their preference for any of the prescribing models

\section{Perceived areas of training needs}

The majority of respondents $(285 / 295 ; 96.6 \%)$ who were willing to be prescribers reported that they would need additional training in order to become prescribers. In addition, all of these respondents strongly agreed or agreed that postgraduate clinical 
courses should be developed to prepare pharmacists for prescribing. The most perceived areas of training need were in the principles of differential diagnosis (81.4\%), pathophysiology of diseases (74.0\%) and interpreting laboratory results (68.1\%). Medication adherence (25.6\%) and communication skills (35.1\%) were reported as areas of least training need (Figure 1).

\section{Potential facilitators and barriers to pharmacist prescribing}

Respondents' views in relation to the potential facilitators and barriers to granting prescribing authority to pharmacists in Nigeria are presented in Table 2. Respondents identified increasing patients' access to care (308/315; 97.8\%), better utilisation of pharmacists' skills $(307 / 315 ; 97.5 \%)$ and ensuring effective use of the limited human resources for health $(290 / 315 ; 92.1 \%)$ as the most likely facilitators. On the other hand, resistance from the medical doctors (299/315; 94.9\%), pharmacists' inadequate skills in diagnosis $(255 / 315 ; 81.0 \%)$ and shortage of pharmacists $(220 / 315 ; 69.8 \%)$ were perceived as the most likely barriers.

\section{Discussion}

Overall, pharmacists showed a positive attitude towards the introduction of pharmacist prescribing in Nigeria. The majority of them supported it and were willing to be prescribers themselves. These findings confirm the qualitative study we conducted with Nigerian stakeholders where the majority of the pharmacists interviewed were strongly supportive of the granting of prescribing authority to them. ${ }^{[2]}$

We consider this to be the first national survey that investigated pharmacists' views on the extension of their clinical roles to include prescribing in Nigeria. The initial design of the project was to recruit participants who were representatives of the pharmacists' population in Nigeria in order to ensure statistical generalisation of the study findings. However, it was not possible to obtain the email addresses of all the registered pharmacists (about 17,000) on the Pharmacists' Council of Nigeria list as many do not have their emails on the councils' database. Therefore, the population in which the respondents of this survey were drawn was a biased one because it excluded Nigerian pharmacists who were not members of the Facebook group of PSN. About $60 \%$ of those contacted for this survey did not participate in the study. This is likely to introduce a nonresponse bias in the findings of this survey. Also, a large proportion of those that responded to the survey were hospital pharmacists, this could be a potential source of bias as respondents of this study might have been those more interested in pharmacist prescribing. Despite these limitations, this study has provided many avenues for future 
research including a larger national survey that would generate generalizable data and to investigate how best to prepare Nigerian pharmacists for a potential role in prescribing. Also, future surveys should investigate the views of other key stakeholders including medical doctors and patients, who are major players in driving medicines policies in Nigeria.

The strong support for pharmacist prescribing seen in this study is unsurprising in view of pharmacists' aspirations for better utilisation of their skills and enhanced clinical autonomy in their practice. These desires are believed to be achievable within the scope of practice of the pharmacist prescriber ${ }^{[3,11]}$ Therefore, such perception would have influenced pharmacists' support for prescribing.

Many facilitators to pharmacist prescribing identified in this survey were linked to its potential benefits. A key benefit identified in this research is the potential of pharmacist prescribing to increase patients' access to care. Increasing patients' access to care is one of the key policy objectives of non-medical prescribing including pharmacist prescribing in countries where it is being practiced including the UK and Canada. ${ }^{[1]}$ Patients in some UK studies have reported an increase in access to care including perceived reduction in appointment delays as a result of nonmedical prescribing. ${ }^{[11,24]}$ This would be of great benefit to patients in Nigeria considering that many patients lack access to medical care as a result of shortage of medical practitioners. In addition, pharmacists' involvement in prescribing could potentially reduce doctors' workload or permit doctors to deal with more complex cases leaving routine or patients with prediagnosed, long term conditions to be seen by the prescribing pharmacists.

Medical resistance was perceived by the majority of respondents (94.9\%) as the most likely barrier to pharmacist prescribing. However, medical resistance is unlikely if pharmacists prescribe in collaboration with doctors. This is because the doctor still maintains the overall control of the prescribing process. In addition, the doctor in a collaborative prescribing arrangement sees the pharmacist as someone who enhances or complements the doctors' role and not doctors' substitute. In contrast, independent pharmacist prescribing may be viewed by doctors as an encroachment into their territory and therefore could attract resistance from doctors. Although the majority of participants of this survey including hospital and community pharmacists reported that they would prefer to prescribe in collaboration with doctors, collaborative prescribing is more likely to be successful within hospital settings in the Nigerian context. Unlike hospital pharmacists, there is currently no system in place to foster collaborative working relationships between doctors and community pharmacists. In addition, community 
pharmacists in Nigeria have no access to patients' medical records maintained by hospitals. As a result, these factors are likely to present a challenge to community pharmacist collaborative prescribing. A limited form of independent prescribing using approved formularies or standard treatment guidelines for minor conditions could be more appropriate for community pharmacy settings in Nigeria. This was the type of prescribing model authorised for community pharmacists in South Africa in order to fill geographical gaps in relation to access to medical prescriber in rural settings. ${ }^{[25]}$ Previous studies in Nigeria have advocated a policy change to allow community pharmacists to treat minor disease conditions. ${ }^{[26,27]}$ Hence, utilising Nigerian community pharmacists in a similar manner to South Africa, offers an opportunity to increase patients access to care particularly in communities underserved by primary care facilities.

The perceived areas of training need identified in this study including training in the principles of differential diagnosis, confirm respondents' concerns that pharmacists' inadequate skills in diagnosis and clinical assessment could be potential barriers to introducing pharmacist prescribing in Nigeria. In many countries where pharmacists are legally allowed to prescribe, those intending to be prescribers are required to undergo additional training to enhance their competence in prescribing. Although training requirements vary across countries, the UK training model appears to be well established and has been evaluated for its appropriateness in meeting the training needs of prescribers. Many supplementary and independent pharmacist prescribers in the UK have reported that the prescribing courses they attended provided them with relevant knowledge and skills for their roles. In addition, the period of learning and practice under a medical prescriber was highly appreciated. ${ }^{[28,29]}$ The UK training curriculum for nonmedical prescribers is based on a single framework that ensures that all prescribers irrespective of their professional background develop comparable set of competencies. ${ }^{[30]}$ Developing similar competencies framework and using it to inform the training of prescribers in Nigeria would be beneficial. Such a competency framework would ensure that all prescribers in Nigeria attain a minimum level of competency in which they can safely and competently prescribe medicines within their jurisdiction.

\section{Conclusion}

Generally, pharmacists showed a positive attitude towards pharmacist prescribing as the majority of them supported it and were willing to be prescribers. However, many pharmacists noted that they will need additional training particularly in the aspects of the principles of differential diagnosis and pathophysiology of diseases in order to take on a prescribing role. This study has provided many avenues for future research including 
how best to prepare Nigerian pharmacists for a potential role in prescribing. Many pharmacists also viewed pharmacist prescribing as an opportunity to promote patients' access to care and the utilisation of pharmacists' skills in Nigeria. This finding has the potential to shape future medicine prescribing policy and pharmacy practice in Nigeria. Nevertheless, a number of barriers to introducing pharmacist prescribing in Nigeria were identified including medical opposition and pharmacists' inadequate skills in clinical assessment and diagnosis.

\section{Acknowledgement}

The authors would like to thank all participants for their valuable time and contributions to this research.

\section{Funding}

No financial support was obtained for this study.

\section{Conflict of interest}

The authors do not have any conflict of interest to declare.

\section{References}

1. Bhanbhro S, Drennan VM, Grant R, Harris R. Assessing the contribution of prescribing in primary care by nurses and professionals allied to medicine: a systematic review of literature. BMC Health Serv Res. 2011; 11:330.

2. Emmerton L, Marriott J, Bessell T, Nissen L and Dean L, 2005. Pharmacists and prescribing rights: review of international developments. J Pharm Pharm Sci. 2005; 8(2): 217-225.

3. Auta A., Strickland-Hodge B, Maz J. Stakeholders' views on granting prescribing authority to pharmacists in Nigeria: a qualitative study. Int J Clin Pharm 2016; DOI:10.1007/s11096-016-0321-6.

4. Doloresco F, Vermeulen LC. Global survey of hospital pharmacy practice. Am J Health Syst Pharm 2009;66(5 Suppl 3):S13-9.

5. Cleary J, De Lima L, Eisenchlas J, Radbruch L, Torode J, Cherny NI. Formulary availability and regulatory barriers to accessibility of opioids for cancer pain in Latin America and the Caribbean: a report from the Global Opioid Policy Initiative (GOPI). Ann Oncol 2013; 24(suppl 11):xi41-xi50.

6. The Misuse of Drugs (Amendment No.2) (England, Wales and Scotland) Regulations 2012. Statutory Instrument No. 973. 2012. 
7. Pharmacists' Scope of Practice in Canada. Canadian Pharmacists Association, 2016. https://www.pharmacists.ca/cpha-ca/assets/File/cpha-on-theissues/ScopeofPracticeinCanada DEC2016.pdf Accessed 15.02.17

8. Bacovsky RA. Pharmacist prescribing: has the momentum started? Can J Hosp Pharm 2012;65(6):421-6.

9. Nissen L. Hospital talk: Pharmacist prescribing-the perfect storm? Australian Journal of Pharmacy 2014;95:29.

10. Hoti K, Sunderland B, Hughes J, Parsons R. An evaluation of Australian pharmacist's attitudes on expanding their prescribing role. Pharm World Sci 2010;32(5):610-21.

11. Stewart DC, George J, Bond CM, Diack HL, McCaig DJ, Cunningham S. Views of pharmacist prescribers, doctors and patients on pharmacist prescribing implementation. Int J Pharm Pract. 2009;17(2):89-94.

12. Cooper R, Anderson C, Avery T, Bissell P, Guillaume L, Hutchinson A, et al. Stakeholders' views of UK nurse and pharmacist supplementary prescribing. $J$ Health Serv Res Policy 2008;13(4):215-21.

13. Lloyd F, Parsons $C$ and Hughes CM. 'It's showed me the skills that he has': pharmacists' and mentors' views on pharmacist supplementary prescribing. Int J Pharm Pract. 2010; 18(1):29-36.

14. National Drug Policy-Nigeria. Federal Ministry of Health, Nigeria and World Health Organisation Abuja, Nigeria, 2005. http://apps.who.int/medicinedocs/documents/s16450e/s16450e.pdf Accessed 31.05.16

15. Ehiri JE, Oyo-Ita AE, Anyanwu EC, Meremikwu MM, Ikpeme MB. Quality of child health services in primary health care facilities in south-east Nigeria. Child Care Health Dev. 2005;31(2):181-91

16. Fagbule $D$, Kalu A. Case management by community health workers of children with acute respiratory infections: implications for national ARI control programme. J Trop Med Hyg. 1995;98(4):241-6.

17. Umar I, Oche MO, Umar AS Patient waiting time in a tertiary health institution in Northern Nigeria. Journal of Public Health and Epidemiology, 2011. 3(2):78-82.

18. Ajayi IO. Patients' waiting time at an outpatient clinic in Nigeria--can it be put to better use? Patient Educ Couns. 2002;47(2):121-6.

19. World Bank. Physicians (per 1,000 people). http://data.worldbank.org/indicator/SH.MED.PHYS.ZS. Accessed 30 March 2016. 
20. Auta A, Maz J, Strickland-Hodge B. Perceived facilitators to change in hospital pharmacy practice in England. Int J Clin Pharm 2015;37(6):1068-75.

21. Auta A, Bala ET, Shalkur D. Generic medicine substitution: a cross-sectional survey of the perception of pharmacists in North-Central, Nigeria. Med Princ Pract 2014;23(1):53-8.

22. ENG J. Sample size estimation: How many individuals should be studied? Radiology, 2003; 227:309-313.

23. Auta A, Strickland-Hodge B, Maz J. Challenges to clinical pharmacy practice in Nigerian hospitals: a qualitative exploration of stakeholders' views. J Eval Clin Pract 2016; 22(5):699-706.

24. Courtenay M, Carey N, Stenner K, Lawton S, Peters J. Patients' views of nurse prescribing: effects on care, concordance and medicine taking. $\mathrm{Br} \mathrm{J}$ Dermatol 2011;164(2):396-401.

25. Ward K, Sanders D, Leng H, Pollock AM. Assessing equity in the geographical distribution of community pharmacies in South Africa in preparation for a national health insurance scheme. Bull World Health Organ. 2014;92(7):482-9

26. Auta, A., Fredrick NC, David S, Banwat SB, Adeniyi MA. Patients' views on their consultation experience in community pharmacies and the potential prescribing role for pharmacists in Nigeria. J Pharm Health Serv Res, 2014; 5:233-236.

27. Oparah AC, Arigbe-Osula EM. Evaluation of community pharmacists' involvement in primary health care. Trop J Pharm Res. 2002; 1(2):67-74.

28. Latter S, Blenkinsopp, Smith A, Chapman S, Tinelli M, Gerard K et al. Evaluation of nurse and pharmacist independent prescribing, 2010. http://eprints.soton.ac.uk/184777/3/ENPIPfullreport.pdf Accessed 31.05.16.

29. Cooper RJ, Lymn J, Anderson C. Learning to prescribe - pharmacists' experiences of supplementary prescribing training in England. BMC Med Educ. 2008; 5;8:57.

30. A competency framework for all prescribers. Royal Pharmaceutical Society, 2016. http://www.rpharms.com/support-pdfs/prescribing-competencyframework.pdf Accessed 24.08.16. 
Tables and figure

Table 1: Demographic characteristics of respondents $(\mathrm{N}=315)$

\begin{tabular}{lcc}
\hline Demographic & $\begin{array}{c}\text { Number of } \\
\text { respondents }\end{array}$ & $\begin{array}{c}\text { Percentage } \\
\text { (\%) }\end{array}$ \\
Gender & 197 & 62.5 \\
Male & 118 & 37.5 \\
Female & & \\
Age group (years) & 73 & 23.2 \\
$21-30$ & 148 & 47.0 \\
$31-40$ & 84 & 26.7 \\
$41-50$ & 10 & 3.2 \\
$>50$ & & \\
Years of experience & 92 & 29.2 \\
$0-5$ & 105 & 33.3 \\
$6-10$ & 60 & 19.0 \\
$11-15$ & 32 & 10.2 \\
$16-20$ & 26 & 8.3 \\
$>20$ & &
\end{tabular}

\begin{tabular}{lcc}
$\begin{array}{l}\text { Hold a master's degree in clinical } \\
\text { pharmacy }\end{array}$ & \\
Yes & 28 & 8.9 \\
No & 287 & 91.1 \\
& & \\
Primary area of practice & & \\
Hospital & 190 & 60.3 \\
Community & 44 & 14.0 \\
Industry & 23 & 7.3 \\
Academic & 28 & 8.9 \\
Administrative & 13 & 4.1 \\
Others & 17 & 5.4 \\
Geopolitical zone & & \\
North-west & 47 & 14.9 \\
North-east & 39 & 12.4 \\
North-central & 88 & 27.9 \\
South-west & 80 & 25.4 \\
South-east & 28 & 8.9 \\
South-south & 33 & 10.5 \\
\hline
\end{tabular}




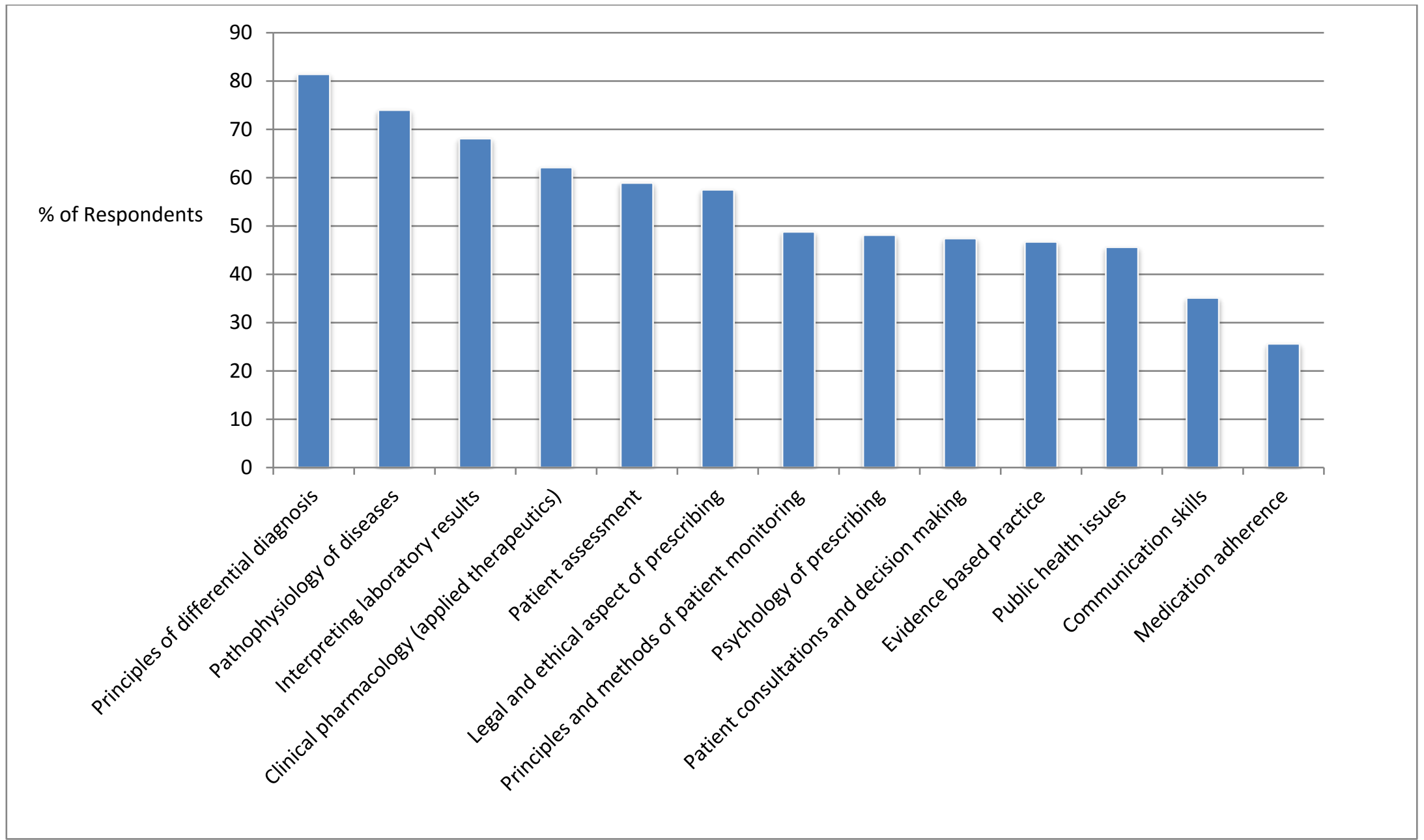

Figure 1: Areas of training need identified by respondents $(\mathrm{N}=\mathbf{2 8 5})$ 
Table 2: Perceived facilitators and barriers to pharmacist prescribing ( $\mathrm{N}=315)$

\begin{tabular}{|c|c|c|c|}
\hline Statements & $\begin{array}{l}\text { SA/A } \\
\text { n (\%) }\end{array}$ & $\begin{array}{c}\text { Unsure } \\
\text { n (\%) }\end{array}$ & $\begin{array}{l}\text { D/SD } \\
\mathrm{n}(\%)\end{array}$ \\
\hline Pharmacist prescribing will increase patients' access to care & $308(97.8)$ & $2(0.6)$ & $5(1.6)$ \\
\hline Pharmacist prescribing will enable better use of pharmacists' professional skills & $307(97.5)$ & $3(1.0)$ & $5(1.6)$ \\
\hline There will be resistance to pharmacist prescribing by the medical doctors & $299(94.9)$ & $4(1.3)$ & $12(3.8)$ \\
\hline Pharmacist prescribing will ensure effective use of the limited human resources in the health sector & $290(92.1)$ & $13(4.1)$ & $12(3.8)$ \\
\hline Pharmacist prescribing will reduce doctors' workload & $273(86.7)$ & $20(6.3)$ & $22(7.0)$ \\
\hline Pharmacist prescribing will save healthcare cost for the government. & $271(86.0)$ & $32(10.2)$ & $12(3.8)$ \\
\hline Pharmacists' skills in making diagnoses are limited & $255(81.0)$ & $17(5.4)$ & $43(13.7)$ \\
\hline $\begin{array}{l}\text { Pharmacist prescribing will minimise the current illegal supply of 'Prescription Only Medicines' without } \\
\text { a prescription in Nigeria }\end{array}$ & $246(78.1)$ & $51(16.2)$ & $18(5.7)$ \\
\hline There are inadequate number of pharmacists in the country to do additional roles & $220(69.8)$ & $20(6.3)$ & $75(23.8)$ \\
\hline Pharmacists lack access to patients' clinical data & $208(66.0)$ & $21(6.7)$ & $86(27.3)$ \\
\hline Pharmacists' training in clinical assessment is limited & $192(61.0)$ & $26(8.3)$ & $97(30.8)$ \\
\hline Pharmacists lack time to take on additional roles & $165(52.4)$ & $20(6.3)$ & $130(41.3)$ \\
\hline Pharmacists lack confidence to take on clinical roles & $141(44.8)$ & $23(7.3)$ & $151(47.9)$ \\
\hline There are inadequate facilities within community pharmacist to allow pharmacist prescribing & $115(36.5)$ & $31(9.8)$ & $169(53.7)$ \\
\hline $\begin{array}{l}\text { Pharmacist prescribing will only happen if technicians are further trained to take on some of the supply } \\
\text { roles of pharmacists }\end{array}$ & $108(34.3)$ & $51(16.2)$ & $156(49.5)$ \\
\hline Pharmacists have negative attitude toward taking up clinical roles & $106(33.7)$ & $34(10.8)$ & $175(55.6)$ \\
\hline Pharmacists have a close working relationship with doctors in patient care & $89(28.3)$ & $32(10.2)$ & $194(61.6)$ \\
\hline Pharmacists will have commercial interest in prescribing & $79(25.1)$ & $69(21.9)$ & $167(53.0)$ \\
\hline There will be conflict of interest with pharmacists acting as both prescribers and dispensers & $61(19.4)$ & $55(17.5)$ & $199(63.2)$ \\
\hline The government is interested in developing pharmacists' clinical roles & $45(14.3)$ & $127(40.3)$ & $143(45.4)$ \\
\hline Pharmacist prescribing will create confusion among the public as to the role of doctors and pharmacists & $33(10.5)$ & $38(12.1)$ & $244(77.5)$ \\
\hline Pharmacist prescribing will increase the likelihood for prescribing errors & $27(8.6)$ & $31(9.8)$ & $257(81.6)$ \\
\hline Pharmacist prescribing will reduce the quality of care the patient receives & $20(6.3)$ & $9(2.9)$ & $286(90.8)$ \\
\hline Pharmacist prescribing will not be accepted by patients & $7(2.2)$ & $11(3.5)$ & $297(94.3)$ \\
\hline Pharmacist prescribing will be more expensive for the patient & $6(1.9)$ & $14(4.4)$ & $295(93.7)$ \\
\hline
\end{tabular}

SA/A: Strongly agree/Agree; D/SD: Disagree/Strongly disagree 
